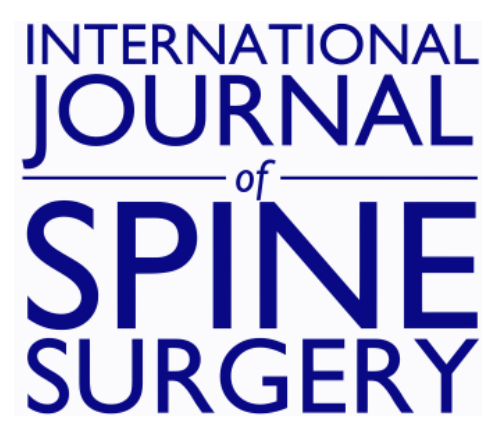

\title{
Anatomic Facet Replacement System (AFRS) Restoration of Lumbar Segment Mechanics to Intact: A Finite Element Study and In Vitro Cadaver Investigation
}

Vijay K. Goel, Ankit Mehta, Jayant Jangra, Ahmed Faizan, Ali Kiapour, Robert W. Hoy and Andrew R. Fauth

Int J Spine Surg 2007, 1 (1) 46-54

doi: https://doi.org/10.1016/SASJ-2006-0010-RR

http://ijssurgery.com/content/1/1/46

This information is current as of April 26, 2023.

Email Alerts Receive free email-alerts when new articles cite this article. Sign up at:

http://ijssurgery.com/alerts

The International Journal of Spine Surgery

2397 Waterbury Circle, Suite 1,

Aurora, IL 60504, Phone: +1-630-375-1432 


\section{Anatomic Facet Replacement System (AFRS) Restoration of Lumbar Segment Mechanics to Intact: A Finite Element Study and In Vitro Cadaver Investigation}

Vijay K. Goel, PhD, Ankit Mehta, BS, Jayant Jangra, BS, Ahmed Faizan, BS, Ali Kiapour, MS, Robert W. Hoy, MEng, and Andrew R. Fauth, PhD

\section{ABSTRACT}

\section{Background}

Many decompression procedures involve complete or partial facetectomy. Spinal fusion usually stabilizes the motion segment after complete facetectomies. However, problems with fusion, such as adjacent-level degeneration, have increased interest in motionpreservation technologies. Facet arthroplasty may become an important posterior motion-preservation device, but its biomechanical literature is sparse.

\section{Methods}

We conducted an in vitro investigation and finite element study to compare the biomechanical effects of an artificial facet system to the intact spine. In the in vitro study, we tested human osteo-ligamentous segments (L3-S1) in intact, injured, and artificial facet-repaired conditions. For the finite element study, we used a 3-dimensional ligamentous L3-S1 segment model. We simulated destabilization in the intact model by removing the facets across the L4-L5 functional unit, then repaired it with appropriately sized facet implants and compared the ranges of motion, facet loads, disc pressures, and device loads. We also analyzed a finite element model with a rigid posterior pedicle-rod fixation system. We subjected the cadaveric specimens and the models to $400 \mathrm{~N}$ of follower load plus a $10 \mathrm{Nm}$ moment in extension, flexion, bending, and rotation. We used a novel technique to apply the follower load in the finite element models such that preload induced minimal vertebral rotation during the range of motion.

\section{Results}

The predicted ranges of motion for the intact and implanted models were consistent with cadaver data. After destabilization and facet replacement, the artificial facet system restored motion in all loading modes to intact values. The implant facet loads were similar to intact facet loads in extension and axial rotation, but less in lateral bending. The intradiscal pressure at the implanted level for the facet replacement device was similar to the intact pressure, whereas with the rigid system the intradiscal pressure was up to $70 \%$ less than the intact pressure. The maximum von-Mises stress predicted in the facet replacement construct was $85 \mathrm{MPa}$ in extension at the bone-pedicle screw interface, compared with $174 \mathrm{MPa}$ in the rigid system. Contact stresses at implant mating surfaces were minimal.

\section{Conclusions}

The artificial facet system replicated natural facet kinematics. The cadaveric ranges of motion and the predicted finite element-based data indicated that the implant can "restore" the normal function of the segment after artificial facet replacement.

\section{Clinical Relevance}

Compared to rigid posterior pedicle-rod fixation, the artificial facet system restored the intact mechanics at the implanted level and may prevent adjacent-level degeneration.

Key Words artificial facet, lumbar spine, biomechanics, finite element technique. SAS Journal. Winter 2007;1: 46-54. DOI: SASJ-2006-0010-RR

\section{INTRODUCTION}

Facet degeneration can lead to several spinal disorders that result in low-back and leg pain. When conservative care such as medication and exercise fails to relieve pain, surgical intervention is considered. In cases such as severe facet tropism, facet hypertrophy, arthritic or degenerated facet joints, and spinal stenosis, partial or full laminectomy with facetectomy surgeries may be warranted to relieve patients of low-back and 
leg pain. However, these decompression procedures may lead to spinal instability. ${ }^{1-5}$ Traditionally, spinal arthrodesis-or, as it is commonly called, fusion-has been the treatment option surgeons use to provide stability to the spine after decompression. However, the recognition of adjacent-level disease as a condition linked to fusion ${ }^{6}$ has spawned an interest in the evaluation of motion-preservation devices as alternatives. The premise of facet joint replacement technology is that the devices will help restore normal spinal motion at the involved levels.

Joint replacement systems for the knee and hip have a long history of clinical success with implants designed to mimic the normal healthy anatomy. ${ }^{7,8}$ These systems also contain instrumentation to precisely and reproducibly place the implants. A deep understanding of the morphology of the facet joint in relation to its biomechanical function is crucial to the development of a facet arthroplasty device. This concept implies that one needs to investigate the biomechanics of the segment after artificial facet placement with the hypothesis that the changes in various parameters compared to the intact segment are minimal. We undertook a 2-part investigation. A well-established in vitro cadaver protocol was used for kinematics. An experimentally validated finite element model was used for the quantification of facet loads, intradiscal pressures, and stresses in various components of the facet replacement system and also in a model stabilized with a pedicle-screw rigid-rod fixation system.

The artificial facet system used for the study was the Anatomic Facet Replacement System (AFRS) (Facet Solutions Inc, Logan, Utah). The system attempts to address posterior lumbar spine pathologies while preserving stability and natural biomechanics. It would thereby mitigate any potential adjacent-level effects that result from the reduction or elimination of motion as seen in semiconstrained dynamic stabilization and fusion devices ${ }^{9}$

The AFRS consists of a precision instrumentation set and an anatomic facet implant family whose design is based upon a comprehensive computed tomographic morphology study of the facet joint. ${ }^{10}$ The system utilizes traditional pedicle screw fixation of its superior and inferior facet implants (Figure 1). The alignment of the implants to the patient's anatomic planes is very precisely controlled by the instrumentation. However, each implant has a polyaxial junction that accommodates $\pm 15^{\circ}$ of variability in pedicle screw placement. The left and right cephalad facet implants are connected by a cross-linking member, which provides additional stability to the construct. The facet implants are manufactured from a wear-resistant alloy, cobalt-chromiummolybdenum. This material has a long and successful history of clinical use in other metal-on-metal total joint replacement systems. ${ }^{11,12}$ Pedicle screws are manufactured of titanium alloy. Titanium plasma spray and hydr oxyapatite coatings are applied to the bone interface surfaces of the facet implants.
Figure 1

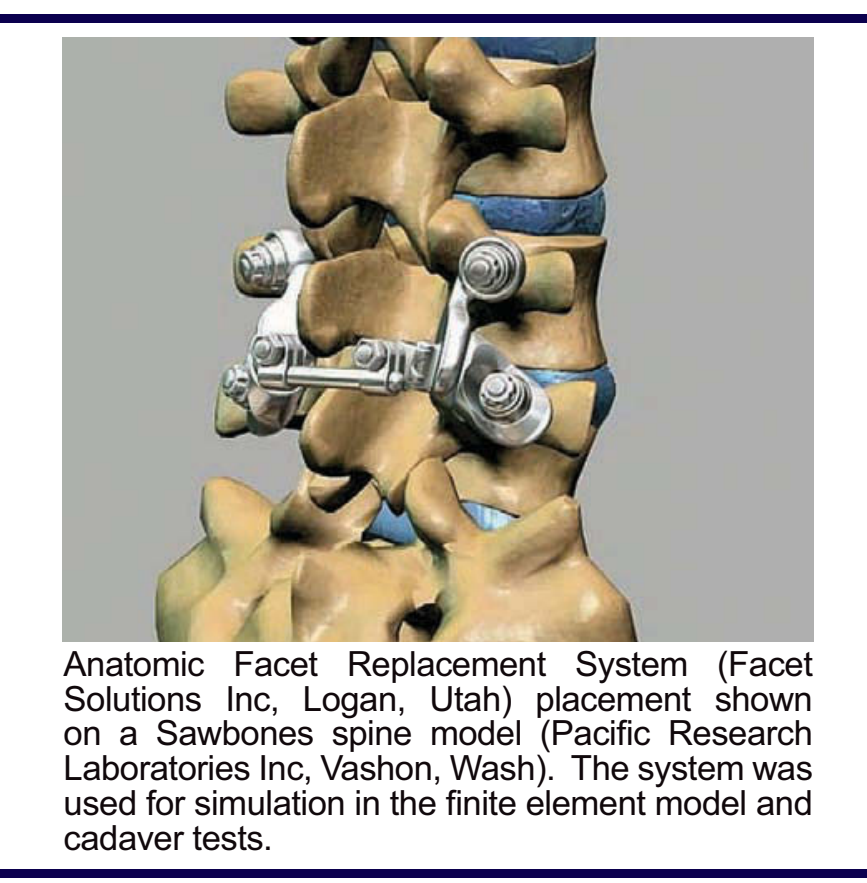

\section{MATERIALS AND METHODS \\ Finite Element Analysis}

Finite Element Model of the Ligamentous L3-S1 Segment The lumbar spine finite element model used in this investigation consisted of a 3-dimensional mesh of L3-S1 ligamentous spinal segment and is an extension of the models previously developed in our laboratory. ${ }^{13-16}$ Details of model formulation and validation are reported elsewhere. ${ }^{13-16}$

\section{Intact L3-S1 Finite Element Model}

The intact L3-S1 finite element model included 31,054 elements and 38,664 nodes (Figures 2a and 2b). Material properties of the various tissues (Table 1) were selected from the literature, including our own experimental data. ${ }^{13-16}$ The apophyseal (facet) joints were simulated with 3-dimensional gap contact elements. These elements transferred force between nodes along a single direction as a specified gap between these nodes closed. The cartilaginous layer between the facet surfaces was simulated using the ABAQUS/Standard version 6.5 (ABAQUS Inc, Providence, RI) "softened contact" parameter, which exponentially adjusted force transfer across the joint, depending on the size of the gap. An initial gap of 0.5 $\mathrm{mm}$ was specified as reported for cadaveric specimens. At full closure, the joint assumed the same stiffness as the surrounding bone. The ligaments were simulated as nonlinear tension-only members. The disc annulus was represented as a composite of fibers embedded in the ground substance and the disc nucleus as "incompressible" fluid encased within the annulus.

\section{Artificial Facet Implanted Model}

The intact model was modified to simulate destabilization 
Figure 2

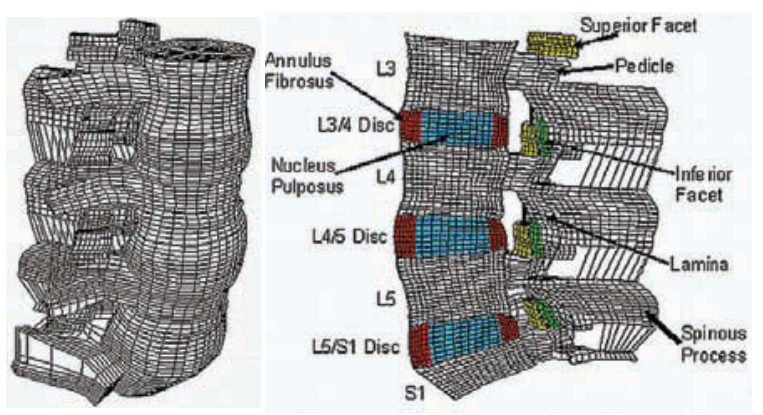

Three-dimensional finite element model of the ligamentous L3-S1 segment: (a) intact model, (b) mid-sagittal cross-section of the model showing important anatomical features.

\section{Table 1}

Material Properties Assigned to Various Spinal Components in the Finite Element Model ${ }^{13-16}$

\begin{tabular}{|l|c|c|}
\multicolumn{2}{|c}{ Young's Modulus (MPa) } & $\begin{array}{c}\text { Poisson's } \\
\text { Ratio }\end{array}$ \\
\hline Cortical bone & 12000.0 & 0.3 \\
\hline Cancellous bone & 100.0 & 0.2 \\
\hline Posterior bone & 3500.0 & 0.25 \\
\hline Annulus (ground) & 4.2 & 0.45 \\
\hline Annulus (fiber) & 175.0 & $\ldots$ \\
\hline Nucleus pulposus & 1.0 & 0.499 \\
\hline Anterior ligament & $7.8(<12 \%), 20.0(>12 \%)$ & 0.3 \\
\hline Posterior ligament & $10.0(<11 \%), 20.0(>11 \%)$ & 0.3 \\
\hline Ligamentum flavum & $15.0(<6.2 \%), 19.5(>6.2 \%)$ & 0.3 \\
\hline Transverse ligament & $10.0(<18 \%), 58.7(>18 \%)$ & 0.3 \\
\hline Capsular ligament & $7.5(<25 \%), 32.9(>25 \%)$ & 0.3 \\
\hline Interspinous ligament & $10.0(<14 \%), 11.6(>14 \%)$ & 0.3 \\
\hline Supraspinous ligament & $8.0(<20 \%), 15.0(>20 \%)$ & 0.3 \\
\hline
\end{tabular}

by removing the facets across the L4-L5 function unit. The geometry of the artificial facet system was imported into ABAQUS/Standard and meshed. All implant components were assigned as cobalt-chromium-molybdenum (Young modulus, E $=241 \mathrm{GPa}$; Poisson ratio, $v=0.3$ ), except the titanium alloy screws (Young modulus, $\mathrm{E}=115 \mathrm{GPa}$; Poisson ratio, $v=0.3$ ). The articulating surfaces of superior and inferior facets of the device were connected to pedicle screws, $6.5 \mathrm{~mm}$ in diameter and $35 \mathrm{~mm}$ long by connecting shafts (Figures $3 \mathrm{a}$ and $3 \mathrm{~b}$ ). The cephalad facets on the 2 sides were also connected to each other by means of another horizontal connecting shaft. The pedicle screws were tied to the holes in the pedicle bone, thereby simulating perfect bone ingrowth. Contacts were defined between the articulating faces of the superior and inferior facets with contact elements from ABAQUS.

\section{Rigid Posterior Pedicle-Rod Fixation Model}

To simulate a pedicle screw-based rigid-rod implant, cylindrical rods of uniform cross section were tied to the superior and
Figure 3
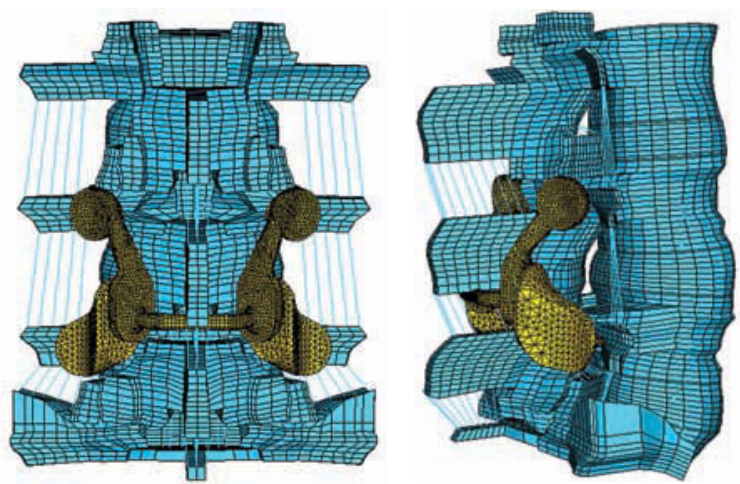

Finite element model of the injured spine repaired with the Anatomic Facet Replacement System: (a) posterior view, (b) side view. A small hole was made in the interspinous ligament to place the transverse rod across the two facets.

inferior pedicle screws, bilaterally (Figures $4 \mathrm{a}$ and $4 \mathrm{~b}$ ). The pedicle screws were tied to the holes in the pedicle bone, thereby simulating perfect bone ingrowth. The titanium screws were $6.0 \mathrm{~mm}$ in diameter.

\section{Boundary and Loading Conditions}

The inferiormost surface of S1 was constrained in all 3 directions. A novel technique was used to apply $400 \mathrm{~N}$ follower load such that its application did not induce any rotation in the vertebrae. Springs were bilaterally attached across each motion segment and iteratively positioned such that load in the spring did not induce any relative rotational motion across the motion segment. The spring on each side was given a pre-tension of $200 \mathrm{~N}$ and spring stiffness was defined as zero. The zero spring constant ensured that deflection in the spring did not affect the pre-tension and, thus, it acted as a rope with constant tension of $200 \mathrm{~N}$ on either side. Moment load of $10 \mathrm{Nm}$ was applied in the intact, injured, and implanted models at the superior L3 endplate in flexion, extension, bending, and axial rotation.

\section{In Vitro Testing}

Specimen Preparation

Fresh ligamentous human lumbar spine specimens (L3-S1) were procured and stored in double plastic bags (Hefty One Zip; Pactiv Corp, Lake Forest, Ill) at $-20^{\circ} \mathrm{C}$. For each specimen, anteroposterior and lateral radiographs were obtained and 6 specimens with good bony and ligamentous integrity were selected for the study. Before testing, the specimens were thawed to room temperature for 10 hours and then cleaned to remove any extraneous fat, muscle, and tissue. The L3 and S1 vertebrae of each specimen were then potted firmly in a mixture of Bondo auto body filler (Bondo MarHyde Corp, Atlanta, Ga) and fiberglass resin (Home-Solution All Purpose; Bondo Marhyde). A loading frame was attached to the L3 vertebra 
Figure 4
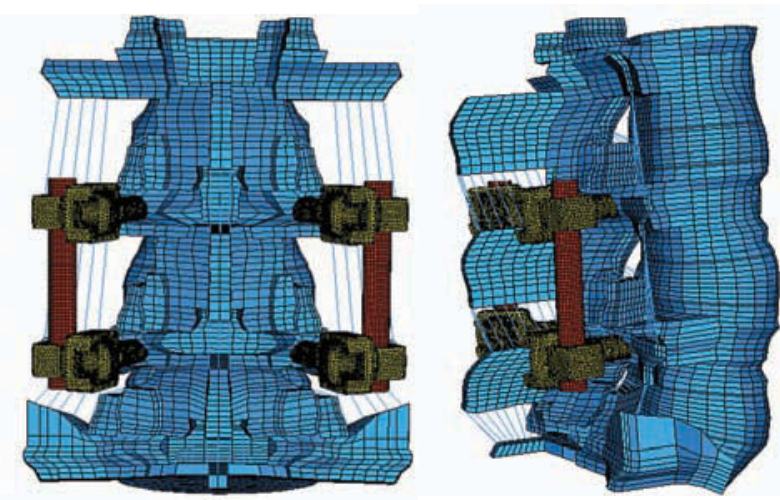

Finite element model simulating pedicle screw-based rigid rod implant: (a) rear view, (b) side view.

before potting. L-shaped Plexiglas markers (Northern Digital Inc, Waterloo, Ontario), each having 3 infrared light-emitting diodes, were secured rigidly to each vertebral body to track its motion with the Optotrak 3020 motion analysis system (Northern Digital Inc). One of the Plexiglas markers was fixed to the base and acted as the reference frame. This specimen preparation procedure was similar to those described in the literature, including our own publications. ${ }^{3,17,18}$

\section{Testing Protocol}

The prepared specimen was mounted on the testing rig and $400 \mathrm{~N}$ of follower load was applied to the specimen by means of cable-and-pulley arrangement (Figure 5). Pure moments of $10 \mathrm{Nm}$ in steps of $2.5 \mathrm{Nm}$ in flexion, extension, bending, and rotation were applied to the specimen by hanging weights to the loading frame. Specimen was sprayed with saline solution once every 30 minutes to prevent drying. After each load step, the spatial data of the infrared light-emitting diodes were acquired with the Optotrak system. From these data, the angular motion of each vertebra was calculated according to the principles of rigid body motion.

Following the testing and data acquisition of the intact motion segment, a neural decompression was simulated by performing only a complete bilateral facetectomy. The ligaments that ran between the spinous processes and lamina of adjacent levels (interspinous, supraspinous, and ligamentum flavum) were left intact. A set of precision instrumentation was then used to prepare bone beds for each of the 4 facet implants. The pedicles were tapped and appropriately sized pedicle screws implanted. Much as in a total hip or knee surgery, a set of trials identical in geometry to the facet implant family was utilized to determine the optimal sizes. The final implants were secured to the bone bed and a cross-linking bar was attached, connecting the cephalad pair of facet implants through a small hole in the interspinous ligament (Figure 6). Motion data were acquired for the destabilized artificial facet system-repaired specimens
Figure 5

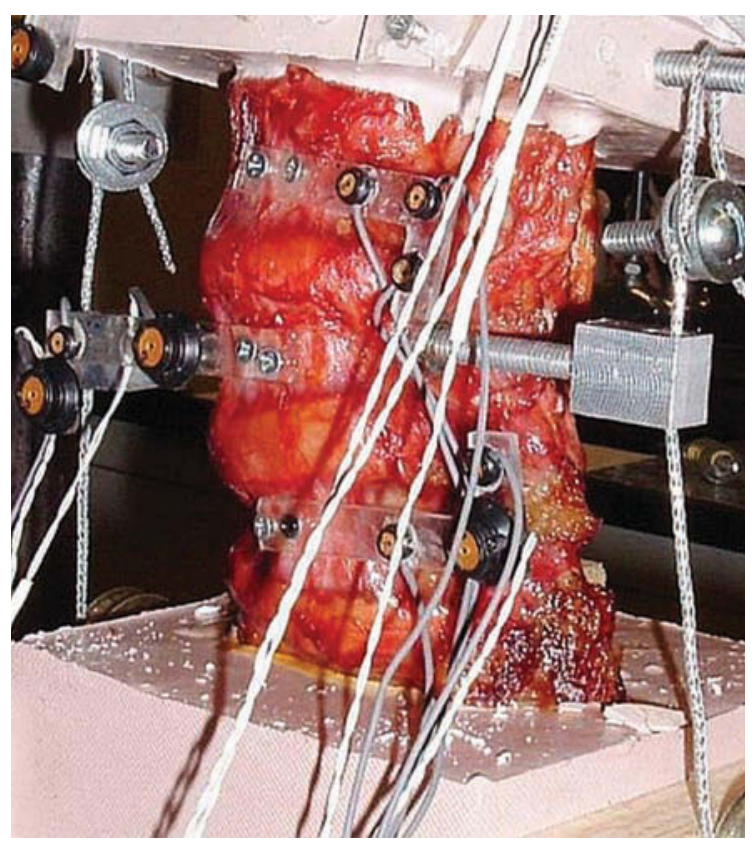

Potted specimen under testing showing LEDS and pulleys for applying follower load.

under the same loading conditions as with the intact specimen. The data were analyzed with 2-tailed paired $t$ tests to determine statistical significance between intact, injured, and repaired specimens.

\section{RESULTS}

The cadaveric study showed that the artificial facet system was able to restore the motion to intact values (Figure 7). On average, motion with the device was only $18 \%$ less than intact motion in extension, $3 \%$ more in flexion, $18 \%$ less in lateral bending, and $15 \%$ less in axial rotation. Two-tailed paired $t$

Figure 6

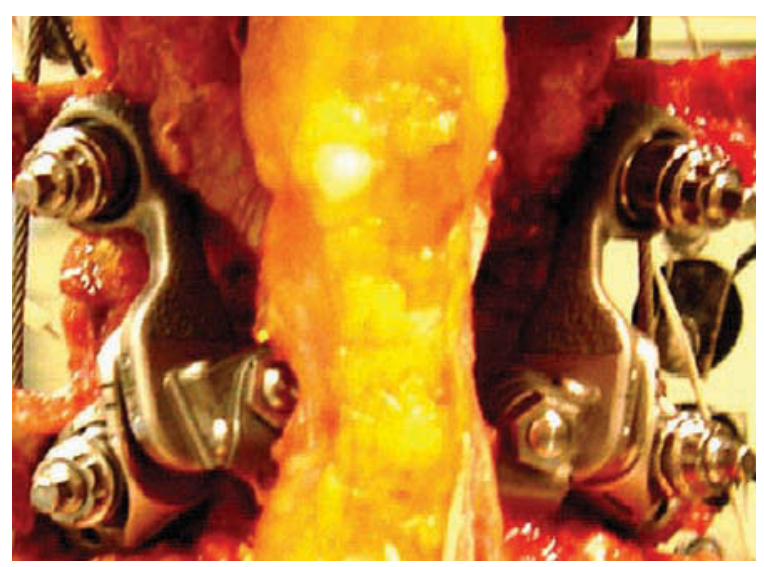

In vitro testing of Anatomic Facet Replacement System-repaired spine segment. The supraspinous ligament and majority of the interspinous ligament were left intact. 
test $P$ values are summarized in Table 2. Significance (at $P<$ $.05)$ was observed in both extension and axial rotation when comparing the destabilized to the facet replacement condition, as expected. Thus, 2 of the facet joint's primary functionsto provide stability in extension and axial rotation-were supported. Although a significant difference was not observed between the intact and destabilized conditions for extension and axial rotation, the $P$ values were much closer to significance than the flexion $P$ values. The variation in cadaveric facet anatomy compared to the uniformity of the facet replacement articular surface geometry may have something to do with the facet replacement data having a smaller standard deviation, particularly in extension.

There were no significant differences observed between the intact and facet replacement conditions. The finite element model-predicted motions in all modes were similar to the mean experimental values (Figure 7). By contrast, finite element analysis showed that the rigid posterior pedicle-rod fixation system reduced the motion significantly, compared to the intact.

Figure 7

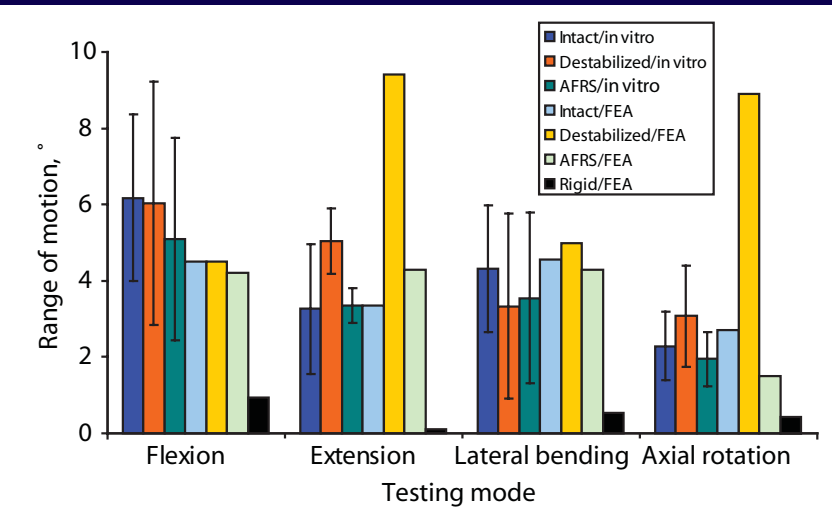

L4-L5 motion for the intact, destabilized, Anatomic Facet Replacement System (AFRS)-repaired, and rigid models: in-vitro and finite element analysis (FEA) results in response to $400 \mathrm{~N}$ follower load and $10 \mathrm{Nm}$ moment. Anovel technique was used to apply preload in the finite element model so that the preload did not induce any rotation of the vertebrae.

Table 2

Cadaver Range of Motion Statistics: 2-Tailed Paired t-Test P Values

\begin{tabular}{|l|c|c|c|}
\multicolumn{1}{|c}{$\begin{array}{c}\text { Destabilized } \\
\text { vs Facet } \\
\text { Replacement }\end{array}$} & $\begin{array}{c}\text { Destabilized } \\
\text { vs Intact }\end{array}$ & $\begin{array}{c}\text { Intact vs Facet } \\
\text { Replacement }\end{array}$ \\
\hline Flexion & .612 & .876 & .520 \\
\hline Extension & $.008^{*}$ & .078 & .913 \\
\hline Lateral Bending & .504 & .057 & .083 \\
\hline Axial Rotation & $.002^{*}$ & .145 & .321 \\
\hline
\end{tabular}

${ }^{*} P<.05$.
Rigid fixation reduced flexion, extension, lateral bending, and axial rotation by $79 \%, 97 \%, 89 \%$, and $85 \%$, respectively, compared to intact motion in the finite element model.

The predicted facet loads for the intact spine model were within the range of those reported in the literature (Table 3, Figures 810). The implant facet loads predicted by the model were very close to the intact values in extension and axial rotation (Figure 11). In flexion, a minimal facet load of $30 \mathrm{~N}$ was found with the device. The facet loads for the rigid fixation system model were very small in comparison.

Finite element study predicted that the intradiscal pressures across the destabilized level increased substantially from intact values, especially in extension (a $136 \%$ increase). The artificial facet system was able to reduce the intradiscal pressure back to the intact values (Figure 12) in all the modes. By contrast, with the rigid system, the pressure across the implanted level was up to $71 \%$ less than intact values in extension.

The peak pedicle-to-bone interface stress in the facet replacement implant was $85 \mathrm{MPa}$ in extension compared with $174 \mathrm{MPa}$ in the rigid system (Figure 13). These values are small compared with a yield stress of $827 \mathrm{MPa}$ for cobalt-chromium ${ }^{28,29}$ and 795 MPa for titanium..$^{30}$ The screws are titanium, which has a yield strength of $795 \mathrm{MPa}$. The maximum contact stress between the opposing artificial facets was $69 \mathrm{MPa}$ in extension.

\section{DISCUSSION}

The range-of-motion data from the cadaveric study elucidated the kinematics of the lumbar spine while enabling us to assess the motion predictions of the finite element model. The primary purpose of using the experimentally validated model was to make predictions regarding facet and implant loading and intradiscal pressures. Reliable data for these parameters can be challenging to obtain experimentally. ${ }^{31,32}$ For example, the in vitro (experimental studies)-based facet loads show a wide variation (from 3\% to 20\%) for several reasons: expected variations in the experimental studies, variations in the facet orientation from specimen to specimen, limitations of the transducer technology used for pressure measurements (e.g., Tekscan vs Fuji film), the ability to accurately calibrate the sensors, and, finally, placement of the transducer itself within the opposing facets (Table 3 and Figures 8-10). Conversely, it is difficult for the finite element model to account for the anatomic variability present in the population. ${ }^{33,34}$ Hence, employing both a theoretical and an experimental approach allows for a more complete investigation of this complex system.

Predicted model and experimental values agree reasonably well for range of motion. Both cadaveric and finite element results showed that the facet replacement implant was able to restore 
Table 3

Predicted Facet Loads Compared With Values From the Literature

\begin{tabular}{|c|c|c|c|}
\hline \multicolumn{4}{|c|}{ Facet Load (N) } \\
\hline Reference & $\begin{array}{l}\text { Pure } \\
\text { Moment } \\
(\mathrm{nm})\end{array}$ & $\begin{array}{c}\text { Finite } \\
\text { Element } \\
\text { Analysis }\end{array}$ & in vitro \\
\hline \multicolumn{4}{|c|}{ Extension } \\
\hline $\begin{array}{l}\text { Lorenz } 1983^{19} \\
\text { (Experimental) }\end{array}$ & 10.0 & & 114.0 \\
\hline $\begin{array}{l}\text { Lorenz } 1983^{19} \\
\text { (Experimental) }\end{array}$ & 10.0 & & 205.0 \\
\hline \begin{tabular}{|l|} 
Dooris $2001^{14}$ \\
(Finite element)
\end{tabular} & 10.0 & 160.0 & \\
\hline $\begin{array}{l}\text { Lee } 2004^{5} \\
\text { (Finite element) }\end{array}$ & 7.5 & 144.0 & \\
\hline \begin{tabular}{|l|} 
Wilson $2004^{21}$ \\
(Experimental)
\end{tabular} & 7.5 & & 13.0 \\
\hline $\begin{array}{l}\text { Cripton } 2005^{22} \\
\text { (Experimental) }\end{array}$ & 7.5 & & 44.0 \\
\hline $\begin{array}{l}\text { Goel } 2005^{23} \\
\text { (Finite element) }\end{array}$ & 10.0 & 155.0 & \\
\hline $\begin{array}{l}\text { Melcher } 2005^{24} \\
\text { (Experimental) }\end{array}$ & 5.0 & & 59.0 \\
\hline \begin{tabular}{|l} 
Moumene $2005^{25}$ \\
(Finite element)
\end{tabular} & 10.0 & 147.0 & \\
\hline Current study & 10.0 & 163.0 & \\
\hline
\end{tabular}

\begin{tabular}{|c|c|c|c|}
\hline $\begin{array}{l}\text { Shendel } 1993^{20} \\
\text { (Experimental) }\end{array}$ & 10 & & 65 \\
\hline $\begin{array}{l}\text { Natarajan } 1999^{26} \\
\text { (Finite element) }\end{array}$ & 7.5 & 38 & \\
\hline $\begin{array}{l}\text { Wilson } 2004^{21} \\
\text { (Experimental) }\end{array}$ & 7.5 & & 85 \\
\hline $\begin{array}{l}\text { Cripton } 2005^{22} \\
\text { (Experimental) }\end{array}$ & 7.5 & & 106 \\
\hline $\begin{array}{l}\text { Goel } 2005^{23} \\
\text { (Finite element) }\end{array}$ & 10 & 160 & \\
\hline $\begin{array}{l}\text { Melcher } 2005^{24} \\
\text { (Experimental) }\end{array}$ & 5 & & 162.25 \\
\hline $\begin{array}{l}\text { Moumene } 2005^{25} \\
\text { (Finite element) }\end{array}$ & 10 & 241 & \\
\hline $\begin{array}{l}\text { Wilson } 2005^{27} \\
\text { (Experimental) }\end{array}$ & 7.5 & & 80 \\
\hline Current study & 10 & 151 & \\
\hline
\end{tabular}

\begin{tabular}{|l|c|c|c|}
\hline \multicolumn{5}{|c|}{ Lateral bending } & 78 \\
\hline $\begin{array}{l}\text { Shendel 199320 } \\
\text { (Experimental) }\end{array}$ & 10 & & 18 \\
\hline $\begin{array}{l}\text { Cripton 200522 } \\
\text { (Experimental) }\end{array}$ & 7.5 & 61 & \\
\hline $\begin{array}{l}\text { Goel 200523 } \\
\text { (Finite element) }\end{array}$ & 10 & 47 & \\
\hline $\begin{array}{l}\text { Moumene 200525 } \\
\text { (Finite element) }\end{array}$ & 10 & 64 & \\
\hline Current study & 10 & & \\
\hline
\end{tabular}

Figure 8

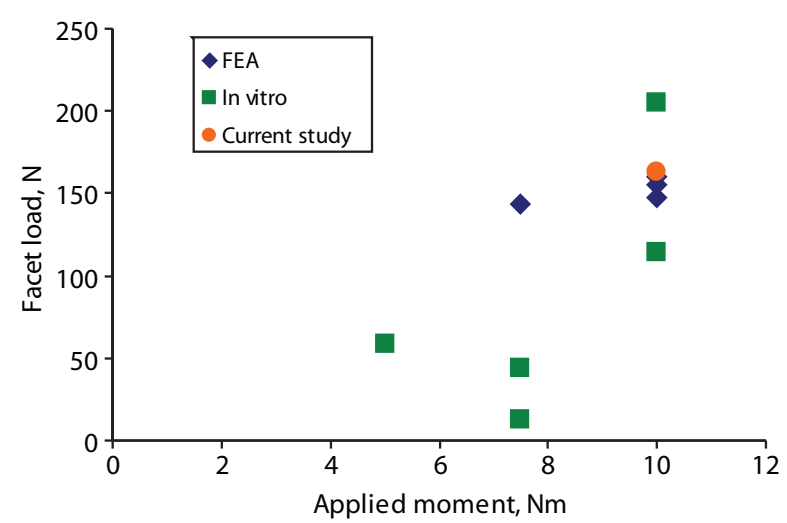

Reported extension facet loads for finite element analysis (FEA), in vitro, and our study.

Figure 9

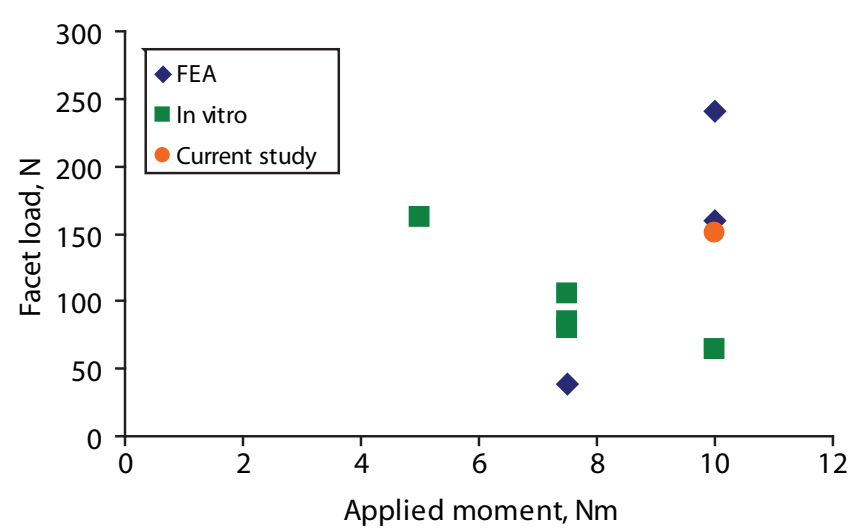

Reported axial rotation facet loads for finite element analysis (FEA), in vitro, and our study.

Figure 10

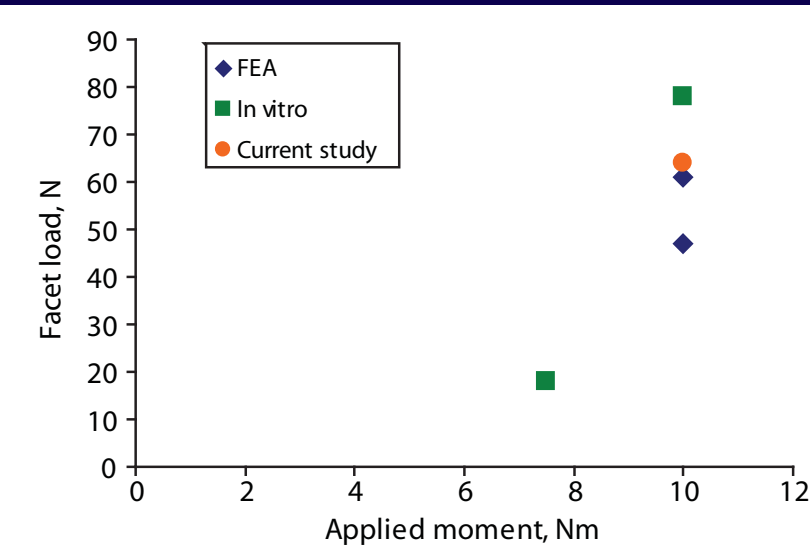

Reported lateral bending facet loads for finite element analysis (FEA), in vitro, and our study. 
Figure 11

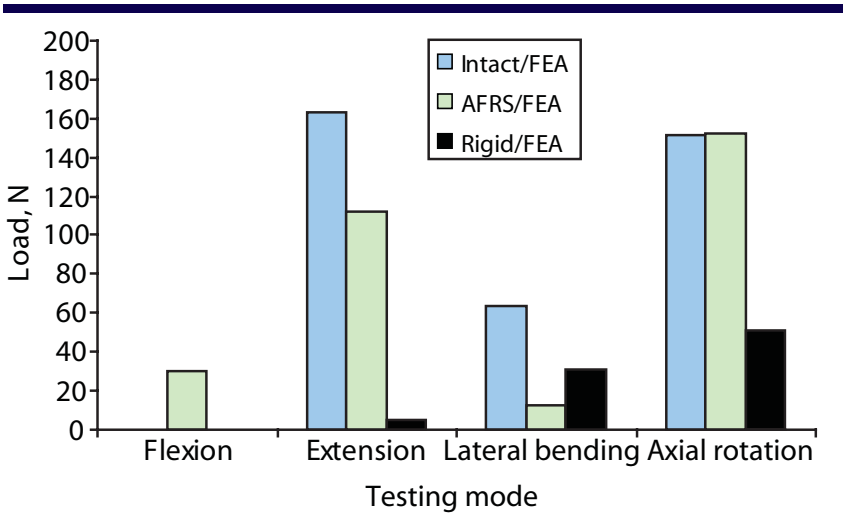

Predicted loads in facets across the implanted level (L4-L5) from finite element analysis (FEA): intact, Anatomic Facet Replacement System (AFRS)-repaired, and rigid models.

\section{Figure 12}

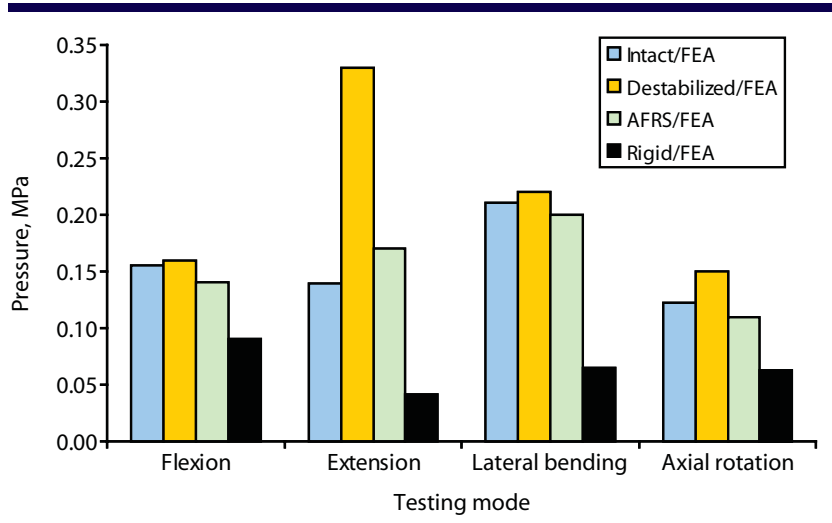

Predicted intradiscal pressure across the implanted level (L4-

L5) from finite element analysis (FEA): intact, destabilized, Anatomic Facet Replacement System (AFRS)-repaired, and rigid models.

\section{Figure 13}

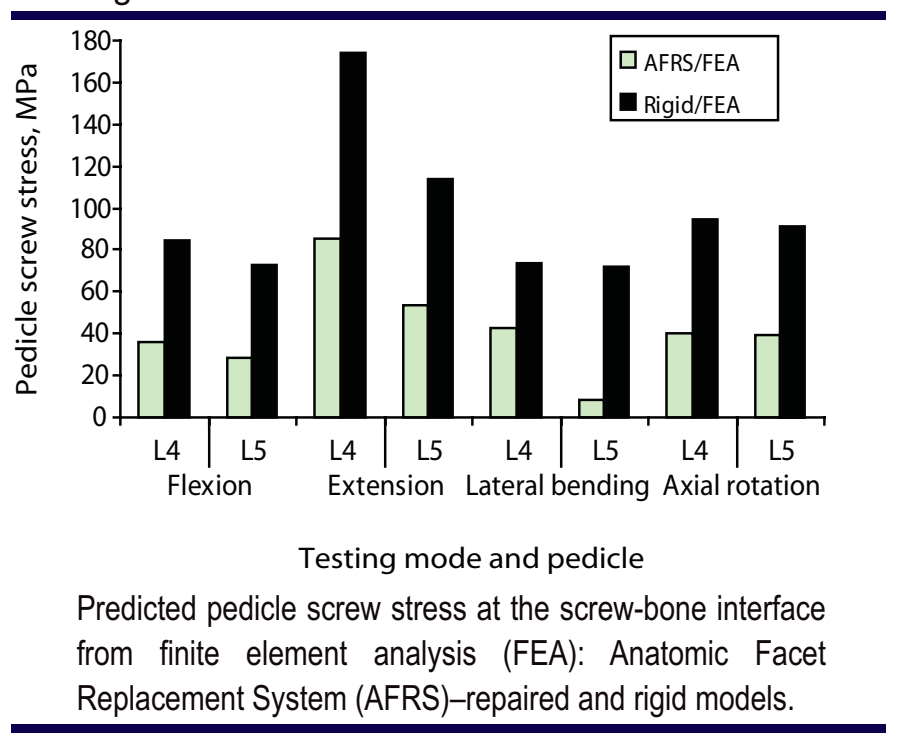

stability after destabilization. Finite element analysis also showed near-equal facet loads with the facet replacement device compared to natural joint loads in extension and axial rotation. The model predicted that intradiscal pressure with the facet replacement device would be very close to the intact values in all the modes of motion and much larger for the destabilized condition. The close agreement of motion and intradiscal pressures across the artificial facet system implanted level with the intact indicates that the device may prevent adjacent level degeneration.

Hybrid protocol is essential to highlight the adjacent level effects following "stabilization," where the implant makes the segment too rigid (e.g., a rigid fixation system) or too flexible (e.g., a dynamic system). The increase in adjacent level loads and intradiscal pressures with the rigid system have been highlighted in other studies by means of hybrid protocol..$^{35}$ However, our data clearly show that motion at the implanted level is very close to the normal and, thus, there is no need to undertake a hybrid protocol testing for this investigation.

Although the rigid fixation system led to increased stability in the finite element model, the predicted screw stresses at the bone-pedicle screw interface were much larger than those of the facet replacement system. Pedicle screw loosening has been a well documented failure mode for rigid fixation systems. ${ }^{36}$ The reduction in pedicle screw stress may afford the facet replacement system better long term fatigue performance. The facet implant's anatomic design most likely contributed to its ability to replicate natural mechanics. However, facet loads and segment mechanics may change somewhat with change in the orientation of the artificial facets. We are currently pursuing additional parametric biomechanical studies to investigate the impact of these variations. Long-term clinical outcome data are needed to determine the true performance of artificial facet systems such as the AFRS.

Vijay K. Goel, PhD, Ankit Mehta, BS, Jayant Jangra, BS, Ahmed Faizan, BS, Ali Kiapour, MS, Robert W. Hoy, MEng, and Andrew R. Fauth, PhD

From the Engineering Center for Orthopaedic Research Excellence, Departments of Bioengineering and Orthopaedic Surgery, Colleges of Engineering and Medicine, University of Toledo, Ohio (Goel, Mehta, Jangra, Faizan, and Kiapour) and Facet Solutions Inc, Logan, Utah (Hoy and Fauth).

The authors declare no conflict of interest.

Address correspondence and reprint requests to Vijay K. Goel, $\mathrm{PhD}$, Engineering Center for Orthopaedic Research Excellence, Departments of Bioengineering and Orthopaedic Surgery, 5046 NI, MS 303, College of Engineering, University of Toledo, Toledo, OH 43606 (email: vijay.goel@utoledo.edu). 
This submission was received January 3, 2007, and accepted for publication February 21, 2007.

Institutional review board approval was not required for this study.

\section{REFERENCES}

1. Knaub MA, Won DS, McGuire R, Herkowitz HN. Lumbar spinal stenosis: indications for arthrodesis and spinal instrumentation. Instr Course Lect. 2005;54:313-319.

2. Abumi K, Panjabi MM, Kramer KM, Duranceau J, Oxland T, Crisco JJ. Biomechanical evaluation of lumbar spinal stability after graded facetectomies. Spine. 1990;15:1142-1147.

3. Yuan PS, Booth RE Jr, Albert TJ. Nonsurgical and surgical management of lumbar spinal stenosis. Instr Course Lect. 2005;54:303-312.

4. Teo EC, Lee KK, Qiu TX, Ng HW, Yang K. The biomechanics of lumbar graded facetectomy under anterior-shear load. IEEE Trans Biomed Eng. 2004;51:443-449.

5. Lee KK, Teo EC, Qiu TX, Yang K. Effect of facetectomy on lumbar spinal stability under sagittal plane loadings. Spine. 2004;29:1624-1631.

6. Shono Y, Kaneda K, Abumi K, McAfee PC, Cunningham BW. Stability of posterior spinal instrumentation and its effects on adjacent motion segments in the lumbosacral spine. Spine. 1998;23:1550-1558.

7. Kelly MA. Patellofemoral complications following total knee arthroplasty. Instr Course Lect. 2001;50:403-407.

8. Ramaniraka NA, Rakotomanana LR, Rubin PJ, Leyvraz P. Noncemented total hip arthroplasty: influence of extramedullary parameters on initial implant stability and on bone-implant interface stresses [in French]. Rev Chir Orthop Reparatrice Appar Mot. 2000;86:590-597.

9. Schmoelz W, Huber JF, Hydegger T, Dipl-Ing, Claes L, Wilke HJ. Dynamic stabilization of the lumbar spine and its effects on adjacent segments: an in vitro experiment. J Spinal Disord Tech. $2003 ; 16: 418-423$.

10. Carl A. Lumbar facet morphology and the development of an anatomic facet joint replacement (AFR). Presented at: 6th Annual Meeting of the Spine Arthroplasty Society; May 9-13, 2006; Montreal, Québec.

11. Howie DW, McCalden RW, Nawana NS, Costi K, Pearcy MJ, Subramanian C. The long-term wear of retrieved McKeeFarrar metal-on-metal total hip prostheses. J Arthroplasty. 2005;203:350-357.
12. Rieker CB, Schon R, Kottig P. Development and validation of a second-generation metal-on-metal bearing: laboratory studies and analysis of retrievals. J Arthroplasty. 2004;19(8 suppl 3):5-11.

13. Kong WZ, Goel VK, Gilbertson LG. Prediction of biomechanical parameters in the lumbar spine during static sagittal plane lifting. J Biomech Eng. 1998;120:273-280.

14. Dooris AP, Goel VK, Grosland NM, Gilbertson LG, Wilder DG. Load-sharing between anterior and posterior elements in a lumbar motion segment implanted with an artificial disc. Spine. 2001;26: E122-E129.

15. Goel VK, Monroe BT, Gilbertson LG, Brinckmann P. Interlaminar shear stresses and laminae separation in a disc. Finite element analysis of the L3-L4 motion segment subjected to axial compressive loads. Spine. 1995;20:689-698.

16. Grosland NM. Spinal Adaptation in Response to Interbody Fusion Systems: A Theoretical Investigation. Iowa City, Iowa: University of Iowa; 1998.

17. Wang ST, Goel VK, Fu CY, et al. Posterior instrumentation reduces differences in spine stability as a result of different cage orientations: an in vitro study. Spine.. 2005;30:62-67.

18. Hitchon PW, Goel V, Rogge T, Dooris A, Drake J, Torner J. Spinal stability with anterior or posterior ray threaded fusion cages. $J$ Neurosurg. 2000;93(1 suppl):102-108.

19. Lorenz M, Patwardhan A, Vanderby R. Load-bearing characteristics of lumbar facets in normal and surgically altered spinal segments. Spine. 1983;8:122-130.

20. Shendel MJ, Wood KB, Buttermann GR, Lewis JL, Ogilvie JW. Experimental measurement of ligament force, facet force, and segment motion in the human lumbar spine. J Biomech. 1993;26:427-438.

21. Wilson D. Does implantation of a dynamic posterior stabilizing device reduce loading in the facet joints? Presented at the 4th Annual Meeting of the Spine Arthroplasty Society, May 4-7, 2004, Vienna, Austria.

22. Cripton $\mathrm{P}$, Oxland $\mathrm{T}$, and Zhu Q. The use of helical axis of motion and facet joint load information in the evaluation of nonfusion spinal implants: Concept and preliminary results. Spine Biomechanics. 2005; 1:22-30.

23. Goel V. Facet loads using an L3-S1 finite element model. Toledo, Ohio: Spine Research Center, University of Toledo and Medical College of Ohio, 2005. 
24. Melcher RP, Milne EL, Harms J, Matthis W, Latta LL. The effects of follower load versus gravity load on the biomechanics of lumbar motion segment units. Presented at the 51st Annual Meeting of Orthopedic Research Society, February 20-23, 2005, Washington DC.

25. Moumene $\mathrm{M}$. The effect of artificial disc placement on facet loading: Mobile core versus fixed core. Spine Biomechanics. 2005;1:38-44.

26. Natarajan R, Andersson G, Patwardhan A, Andriacchi T. Study on effect of graded facetectomy on change in lumbar motion segment torsional flexibility using three-dimensional continuum contact representation for facet joints. J Biomech Eng. 1989;121:215-221.

27. Wilson DC, Niosi CA, Zhu QA, Oxland TR, Wilson DR. Accuracy and repeatability of a new method to measure facet loads in the lumbar spine. Presented at the 51st Annual Meeting of the Orthopedic Research Society, February 20-23, 2005, Washington, DC.

28. ASTMF1537Standard Specification for Wrought Cobalt-28 Chromium6 Molybdenum Alloy for Surgical Implants. West Conshohocken, Pa: American Society for Testing and Materials International; 2006.

29. ASTM F799 Standard Specification for Cobalt-28 Chromium-6 MolybdenumAlloy Forgings for SurgicalImplants. WestConshohocken, Pa: American Society for Testing and Materials International; 2006.

30. ASTM F136 Standard Specification for Wrought Titanium-6 Aluminum4 Vanadium ELI (Extra Low Interstitial) Alloy for Surgical Implant Applications. West Conshohocken, Pa: American Society for Testing and Materials International; 2006.

31. Ledet EH, Tymeson MP, DiRisio DJ, Cohen B, Uhl RL. Direct realtime measurement of in vivo forces in the lumbar spine. Spine $J$. 2005;5:85-94.

32. Wilson DC, Niosi CA, Zhu QA, Oxland TR, Wilson DR. Accuracy and repeatability of a new method for measuring facet loads in the lumbar spine. J Biomech. 2006;39:348-353.

33. Masharawi Y, Rothschild B, Dar G, et al. Facet orientation in the thoracolumbar spine: three-dimensional anatomic and biomechanical analysis. Spine. 2004;29:1755-1763.

34. Boden SD, Riew KD, Yamaguchi K, Branch TP, Schellinger D, Wiesel SW. Orientation of the lumbar facet joints: association with degenerative disc disease. J Bone Joint Surg Am. 1996;78:403-411.

35. Goel VK, Grauer JN, Patel TC, et al. Effects of Charité artificial disc on the implanted and adjacent spinal segments mechanics using a hybrid testing protocol. Spine. 2005;30:2755-2764.
36. Hasegawa T, Inufusa A, Imai Y, Mikawa Y, Lim T, An HS. Hydroxyapatite-coating of pedicle screws improves resistance against pull-out force in the osteoporotic canine lumbar spine model: A pilot study. Spine J. 2005;5:239-243.

\section{WINTER 2007 - VOLUME 01 - ISSUE 01}

